\title{
Association of mineral metabolism biomarkers with chronic kidney disease in Chinese adults
}

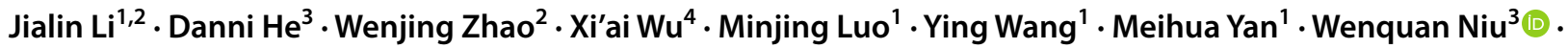 \\ Ping $\mathrm{Li}^{1}$
}

Received: 29 June 2020 / Accepted: 22 February 2021 / Published online: 16 March 2021

(c) The Author(s) 2021

\begin{abstract}
Background We aimed to examine the association of three mineral metabolism markers, including serum calcium, inorganic phosphorus, and intact parathyroid hormone with the risk of chronic kidney disease (CKD) at all stages.

Methods This retrospective cohort study involved 3563 participants, including 3274 CKD patients and 289 healthy controls. CKD is diagnosed according to clinical guidelines from the 2012 KDIGO. Effect sizes are expressed odds ratio (OR) and 95 confidence interval (CI).

Results After propensity score matching, per $0.5 \mathrm{mg} / \mathrm{dL}$ increment of inorganic phosphorus was significantly associated with 1.33-, 1.61-, and 2.85-fold increased risk of CKD at stages 1-2, 4, and 5, respectively. Regarding per $8 \mathrm{pg} / \mathrm{mL}$ increment of intact parathyroid hormone, significance was only noted for stage 5. In subsidiary analyses, the risk prediction of mineral metabolism markers under study was more evident in males and hypertensive subjects. A nomogram prediction model was constructed based on age, sex, and three mineral metabolism markers for CKD, with decent accuracy.

Conclusions Our findings indicate that serum calcium was associated with all-stage CKD risk, whereas the association for inorganic phosphorus and intact parathyroid hormone was significant at advanced stages.
\end{abstract}

Keywords Chronic kidney disease $\cdot$ Interaction $\cdot$ Mineral metabolism biomarkers $\cdot$ Propensity score matching $\cdot$ Risk and severity

Jialin Li and Danni He are shared first authors.

Wenquan Niu

niuwenquan_shcn@163.com

Ping Li

1p8675@163.com

1 Beijing Key Lab Immune-Mediated Inflammatory Diseases, Institute of Clinical Medical Science, China-Japan Friendship Hospital, Beijing, China

2 Department of Nephrology, Beijing Hospital of Traditional Chinese Medicine, Capital Medical University, Beijing, China

3 Institute of Clinical Medical Sciences, China-Japan Friendship Hospital, Beijing, China

4 Department of Endocrinology, China-Japan Friendship Hospital, Beijing, China

\section{Introduction}

Chronic kidney disease constitutes a worldwide health problem due to its high prevalence and absolute burden. The global statistics show that the prevalence of chronic kidney disease is estimated to be $8-16 \%$ [1, 2]. In China, chronic kidney disease is a leading cause of death, and it affects approximately $10.8 \%$ of adults $[3,4]$. It is imperative to curb the epidemic of chronic kidney disease by characterizing the prodromal features of chronic kidney disease at different stages [5].

It is well known that chronic kidney disease is complicated by the presence of abnormalities that reflect disruption in the excretory, metabolic, and endocrine function of the kidney, leading to a dysfunction of mineral metabolism [6-8]. Evidence from clinical and epidemiologic studies indicates that abnormalities of mineral metabolism, such as secondary hyperparathyroidism, hyperphosphatemia, and hypocalcemia, are commonly seen in patients with kidney failure and are associated with an increased risk 
for Chronic kidney disease-Mineral and Bone Disorder (CKD-MBD), vascular calcification, and cardiovascular events [9-11]. Some researchers reported that some mineral metabolism markers maintained within normal laboratory ranges until chronic kidney disease is advanced [12-14]. Currently, a majority of clinical investigations focused on the changes in phosphorus, calcium, and parathyroid hormones mainly in patients with stages 3-5 chronic kidney disease or dialysis patients [15-17]. Available data on the association of mineral metabolism markers with early-stage chronic kidney diseases are particularly sparse in the medical literature.

To fill this research gap and yield more information, we in a large retrospective cohort study aimed to examine the association of three mineral metabolism markers, including serum calcium (corrected by serum albumin, the same below), inorganic phosphorus, and intact parathyroid hormone with the risk of chronic kidney disease at all stages among Chinese adults, especially at early-stage. To facilitate clinical application, we constructed a nomogram prediction model of the severity of CKD based on significant attributes.

\section{Methods}

\section{Study subjects}

This study involved a total of 5294 subjects $18-80$ years of age who were retrospectively recruited from Department of Endocrinology and Department of Nephrology at China-Japan Friendship Hospital during the period between January 2010-December 2018. The conduct of this study received ethical approval from China-Japan Friendship Hospital Ethics Committee and conformed to the principles of the Declaration of HELSINKI. All study subjects provided informed consent prior to participation.

\section{Eligible criteria}

Among 5294 initially recruited subjects in this study, 1731 were excluded from the analysis because of specific reasons listed below: (i) reporting of receiving dialysis or kidney transplantation; (ii) missing data on serum creatinine and urinary albumin-to-creatinine ratio; (iii) use of oral drugs affecting mineral metabolism, such as Lanthanum carbonate, aluminum binders, calcium salts, Calcitriol or vitamin D; (iv) women in pregnancy; (v) diagnosis of diabetic ketoacidosis, acute cardiovascular events, or other severe disorders including tumors. So, the present analysis involved 3563 study subjects who had complete data.

\section{Sample size}

Out of 3563 qualified subjects, 3274 were confirmed to have CKD at all stages, and they formed the case group. The remaining 289 subjects who had no clinical signs of CKD were in the control group.

\section{CKD diagnosis}

CKD is diagnosed if estimated glomerular filtration rate is less than $60 \mathrm{ml} / \mathrm{min} / 1.73 \mathrm{~m}^{2}$ or albuminuria is presented based on the clinical practice guidelines from the Kidney Disease Improving Global Outcomes (KDIGO) in 2012 [18]. Glomerular filtration rate is calculated according to the 2009 CKD Epidemiology Collaboration (CKD-EPI) equation, which is gender-specific and was confirmed by many previous reports [19-23].

Because most patients with CKD had proteinuria measured only one time, persistent proteinuria was not defined in this study.

\section{CKD stages}

According to the KDIGO guidelines in 2012, patients with CKD were divided into four groups, that is, stage $1-2$, stage 3 , stage 4 , and stage 5 [18].

In this present study, 471, 544, 1214, and 1045 patients were diagnosed to have CKD at stage 1-2, stage 3, stage 4, and stage 5 , respectively.

\section{Clinical and biochemical markers}

Besides age and sex, hypertension and diabetes mellitus were diagnosed at the time of recruitment. Hypertension was defined as systolic blood pressure $\geq 140 \mathrm{mmHg}$, diastolic blood pressure $\geq 90 \mathrm{mmHg}$, or the current use of antihypertensive agents [24]. Diabetes mellitus was defined as fasting plasma glucose $\geq 7.0 \mathrm{mmol} / \mathrm{L}$ or taking hypoglycemic drugs or receiving parenteral insulin therapy [25].

Venous blood was taken in the fasting state. The reference ranges of serum calcium, inorganic phosphorus, and intact parathyroid hormone are $2.51-5.52 \mathrm{mg} / \mathrm{dL}, 8.0-11 \mathrm{mg} / \mathrm{dL}$, and $12-88 \mathrm{pg} / \mathrm{mL}$, respectively. All assays were conducted at the Clinical Laboratory for Endocrinology, China-Japan Friendship Institute of Clinical Medical Sciences.

\section{Statistical analyses}

To assess whether baseline characteristics differed significantly across cases with CKD at different stages and the controls, the $\chi^{2}$ test for categorical variables and Wilcoxon 
rank sum test for continuous variables were used. To assess the association of mineral metabolism markers with the risk and severity of CKD, Logistic regression analysis was performed before and after adjusting for covariates. To allow for balancing of covariates between cases and controls, propensity score matching on age, gender, diabetes, and hypertension was conducted. Risk magnitude is weighted using odds ratio (OR) and its $95 \%$ confidence interval (95\% CI).

To assess prediction accuracy after adding each mineral metabolism marker to the basic model, net reclassification improvement and integrated discrimination improvement $[26,27]$ were calculated to judge the discrimination capability of significant mineral metabolism markers. Calibration capability was assessed using the $-2 \log$ likelihood ratio test, Akaike information criterion, and Bayesian information criterion to inspect how closely the prediction probability for the addition of significant mineral metabolism markers reflected the actual observed risk and the global fit of modified risk model.

To illustrate the interaction between mineral metabolism markers, the "rgl" package in the R Project for Statistical Computing (available at the website https://www.r-proje ct.org/) was adopted to plot three-dimension surface. The core of "rgl" package is a shared library that acts as an interface between R and OpenGL.

The STATA software Release 14.1 (StataCorp, TX, USA) was used for data cleaning and statistical analyses unless otherwise indicated [28]. Statistics were adjusted for multiple testing using a Bonferroni correction. Without prior notice, statistical significance was set at a probability of less than $5 \%$.

\section{Results}

\section{Baseline characteristics}

Table 1 shows the baseline characteristics of study subjects in this study. Cases with stages 1-4 CKD were older than controls, while cases with stage 5 were younger. Sex differed significantly between cases and controls, except for stage $3 \mathrm{a}$ and stage $3 \mathrm{~b}$ CKD. Percentages of hypertension and diabetes mellitus were higher in cases with stages 4-5 CKD than in controls.

Figure 1 displays the distributions of three mineral metabolism markers in both cases and controls. Serum calcium concentrations were consistently lower in cases with CKD at all stages than controls, yet the concentrations of intact parathyroid hormone were consistently higher. For inorganic phosphorus, only cases with stages 4-5 CKD had higher concentrations than controls.

\section{Correlation analyses}

The correlation between serum calcium, inorganic phosphorus, and intact parathyroid hormone in all study subjects is presented in Fig. 2. The correlation coefficients of three mineral metabolism markers were relatively small, and so all three mineral metabolism markers were retained in the following analyses.

\section{Overall risk prediction for CKD}

Table 2 shows the risk prediction of mineral metabolism markers under study for CKD at different stages after propensity score weighting and adjustment for confounding factors. After applying Bonferroni correction to account for multiple testing with respect to 16 comparisons, statistical significance was recorded if the probability is less than $0.05 / 16$, viz. 0.003 . Per $0.5 \mathrm{mg} / \mathrm{dL}$ increment in serum calcium was significantly associated with $28-45 \%$ reduced risk of CKD at all stages. For inorganic phosphorus, per $0.5 \mathrm{mg} / \mathrm{dL}$ increment was significantly associated with 1.33-, 1.61-, and 2.85-fold increased risk of CKD at stages $1-2,4$, and 5, respectively. For calciumphosphorus product, per $5 \mathrm{mg}^{2} / \mathrm{dL}^{2}$ increment was significantly associated with 1.28- and 2.19-fold increased risk of CKD at stages 4 and 5, respectively. Regarding intact parathyroid hormone, significance was only noted for stage 5 .

\section{Subsidiary risk prediction for CKD}

Table 3 shows the risk prediction of mineral metabolism markers under study for CKD at different stages according to age, sex, hypertension, and diabetes mellitus, respectively.

When study subjects were grouped by sex, the association between phosphorus and calcium-phosphorus product with stage 5 CKD was stronger in men than in women. Regarding intact parathyroid hormone, significance was noticed for the association with stage 5 in men, and there was no observable significance in women across all stages.

By hypertension, the prediction of mineral metabolism markers under study for CKD was significant at stages 1, 4 (except for calcium-phosphorus product), and 5. By diabetes mellitus, inorganic phosphorus and calcium-phosphorus product can predict the advanced stages of CKD, irrespective of having diabetes mellitus. Intact parathyroid hormone was a predictor for stage 4 CKD in diabetic patients, and no significance was noted in nondiabetic patients across all stages.

\section{Prediction of benefits from mineral metabolism markers}

Table 4 shows the prediction accuracy gained by adding mineral metabolism markers to the basic model. From 
Table 1 Baseline characteristics of study subjects in this study

\begin{tabular}{|c|c|c|c|c|c|c|}
\hline \multirow[t]{2}{*}{ Characteristics } & \multirow[t]{2}{*}{ Controls } & \multirow[b]{2}{*}{ Stage $1-2$} & \multicolumn{4}{|c|}{ Cases with chronic kidney disease } \\
\hline & & & Stage $3 a$ & Stage $3 b$ & Stage 4 & Stage 5 \\
\hline Sample size & 289 & 471 & 172 & 372 & 1214 & 1045 \\
\hline Age (years) & $62(53-69)$ & $68(56-75)^{* *}$ & $71(64-77)^{* *}$ & $73(66-78)^{* *}$ & $70(60-76)^{* *}$ & $59(47-68)^{* *}$ \\
\hline Male $(n, \%)$ & $236,81.7$ & $325,69^{* *}$ & $126,73.2^{* *}$ & $302,81.1^{* *}$ & $819,67.5^{* *}$ & $(588,56.3)^{* *}$ \\
\hline $\begin{array}{l}\text { Hypertension }(n, \\
\%)\end{array}$ & $175,60.6$ & $308,65.4$ & $110,64.0$ & $244,65.6$ & $875,72.1^{* *}$ & $(821,78.36)^{* *}$ \\
\hline Diabetes $(n, \%)$ & $111,38.4$ & 179,38 & $66,38.4$ & 145,39 & $544,44.8^{*}$ & $356,34.1$ \\
\hline $\mathrm{TG}(\mathrm{mmol} / \mathrm{L})$ & $1.38(1.00-1.90)$ & $1.320(0.94-2.03)$ & $1.34(0.93-1.96)$ & $1.37(0.95-1.95)$ & $1.51(1.05-2.20)^{* *}$ & $1.54(1.08-2.19)^{* *}$ \\
\hline $\mathrm{TC}(\mathrm{mmol} / \mathrm{L})$ & $4.30(3.52-4.96)$ & $4.02(3.08-4.80)^{* *}$ & $3.69(2.93-4.52)^{* *}$ & $3.73(2.96-4.58)^{* *}$ & $3.95(3.16-4.94)^{* *}$ & $4.180(3.45-4.99)$ \\
\hline LDL-C (mmol/L) & $2.56(1.98-3.08)$ & $2.29(1.59-2.92)^{* * *}$ & $2.09(1.48-2.73)^{* * *}$ & $2.12(1.50-2.76)^{* * *}$ & $2.29(1.64-3.06)^{* * *}$ & $2.42(1.88-3.09)$ \\
\hline $\mathrm{HDL}-\mathrm{C}(\mathrm{mmol} / \mathrm{L})$ & $1.01(0.84-1.21)$ & $0.97(0.72-1.22)^{*}$ & $0.87(0.63-1.09)^{* *}$ & $0.85(0.61-1.06)^{* *}$ & $0.91(0.68-1.17)^{* * *}$ & $1.00(0.78-1.24)$ \\
\hline $\operatorname{HbA1c}(\%)$ & $6.10(5.50-7.10)$ & $6.20(5.50-7.20)$ & $6.30(5.70-7.20)^{*}$ & $6.60(5.90-7.40)^{*}$ & $6.40(5.70-7.30)^{*}$ & $5.90(5.30-6.70)^{* *}$ \\
\hline $\mathrm{UA}(\mu \mathrm{mol} / \mathrm{L})$ & $333(285-387)$ & $314(218-444)$ & $379(270-500)^{* *}$ & $390(278-520)^{* *}$ & $442(345-548)^{* *}$ & $404(316-502)^{* *}$ \\
\hline $\mathrm{SCr}(\mu \mathrm{mol} / \mathrm{L})$ & $75.03(66.10-85)$ & $\begin{array}{l}77.40(62.90- \\
92.65)\end{array}$ & $120.8(110-168)^{* *}$ & $169(138-189)^{* *}$ & $236(203.3-283)^{* * *}$ & $\begin{array}{l}635.9(463.6- \\
859.0)^{* *}\end{array}$ \\
\hline ACR $(\mathrm{mg} / \mathrm{g})$ & $5.70(4.20-9.10)$ & $\begin{array}{l}64.80(44.10- \\
80.30)^{* * *}\end{array}$ & $\begin{array}{l}19.90(6.60- \\
32.10)^{* * *}\end{array}$ & $\begin{array}{l}23.70(19.50- \\
82.10)^{* *}\end{array}$ & $\begin{array}{c}126.9(36.1- \\
317.3)^{* * *}\end{array}$ & $\begin{array}{c}220.6(126.3- \\
429.5)^{* *}\end{array}$ \\
\hline BUN (mmol/L) & $5.44(4.46-6.75)$ & $9.07(5.72-14.88)^{* *}$ & $\begin{array}{l}9.65(7.83- \\
13.76)^{* *}\end{array}$ & $\begin{array}{c}13.65(10.76- \\
17.83)^{* * *}\end{array}$ & $\begin{array}{l}15.20(11.83- \\
20.12)^{* * *}\end{array}$ & $\begin{array}{l}21.24(16.10- \\
27.36)^{* * *}\end{array}$ \\
\hline $\mathrm{Ca}(\mathrm{mg} / \mathrm{dL})$ & $8.88(8.56-9.2)$ & $8.44(7.86-8.96)^{* *}$ & $8.41(7.92-8.91)^{* * *}$ & $8.40(7.90-8.83)^{* * *}$ & $8.48(7.88-8.96)^{* * *}$ & $8.44(7.8-9.16)^{* *}$ \\
\hline IP (mg/dL) & $3.44(3.10-3.84)$ & $3.41(2.69-4.15)$ & $3.42(2.93-4.09)$ & $3.37(2.65-4.03)$ & $3.94(3.29-4.65)^{\text {*** }}$ & $5.05(4.06-6.26)^{* * *}$ \\
\hline i-PTH (pg/mL) & $34.3(28.6-53.7)$ & $\begin{array}{l}86.55(39.95- \\
171.5)^{* * *}\end{array}$ & $60.6(38.2-96.4)^{* *}$ & $65(40.2-99.7)^{* *}$ & $82.05(45-130)^{* *}$ & $174.6(72.20-333)$ \\
\hline
\end{tabular}

$P$ values are calculated by Wilcoxon rank sum tests for continuous variables expressed as median (interquartile range) and $\chi^{2}$ tests for categorical variables expressed as count and percent

$T G$ triglycerides, $T C$ total cholesterol, $L D L-C$ low-density lipoprotein cholesterol, $H D L-C$ high-density lipoprotein cholesterol, $H b A 1 c$ hemoglobin A1c, $U A$ uric acid, $S c r$ serum creatinine, $A C R$ albumin-to-creatinine ratio, $B U N$ blood urea nitrogen, $I P$ inorganic phosphorus, $C a$ serum calcium, $i-P T H$ intact parathyroid hormone

${ }^{*} P<0.05$

${ }^{* *} P<0.01$

calibration aspect, reduction in both Akaike information criterion and Bayesian information criterion statistics was greater than 10 after adding serum calcium and intact parathyroid hormone to the basic model across all stages of CKD, and for inorganic phosphorus, reduction in both statistics was greater than 10 only at stages $4-5$. Additionally, for stages $1-4$, adding serum calcium or intact parathyroid hormone can significantly improve prediction performance, and for stage 5, significance was seen after adding any of three mineral metabolism markers, as reflected by likelihood ratio test, net reclassification improvement, and integrated discrimination improvement.

\section{Nomogram prediction model}

To facilitate clinical application, a nomogram prediction model was constructed on the basis of age, sex, and three mineral metabolism markers for stage 1-2, 3, 4, and 5 CKD, respectively (Fig. 3). The predictive accuracy and discriminative capability of all nomogram prediction models were assessed by concordance index, which was over $80 \%$ across all stages, indicating significant improvement in model performance.

Taking stage 4 as an example, assuming a men aged 45 years old ( 20 points) with serum calcium of $8 \mathrm{mg} / \mathrm{dL}$ ( 25 points), inorganic phosphorus of $6 \mathrm{mg} / \mathrm{dL}$ (42 points), intact parathyroid hormone of $100 \mathrm{pg} / \mathrm{mL}$ (20 points), the probability of having stage 4 CKD was estimated to be $90 \%$.

\section{Discussion}

The aim of this retrospective study was to examine the association of three mineral metabolism markers with risk of different stages of CKD among Chinese adults. The key finding is that elevated concentrations of serum calcium were associated with reduced risk of all-stage CKD, whereas that of inorganic phosphorus, calcium-phosphorus product, 
Fig. 1 Distributions of serum inorganic phosphorus (IP), serum calcium $(\mathrm{Ca})$, and intact parathyroid hormone (i-PTH) in both cases and controls
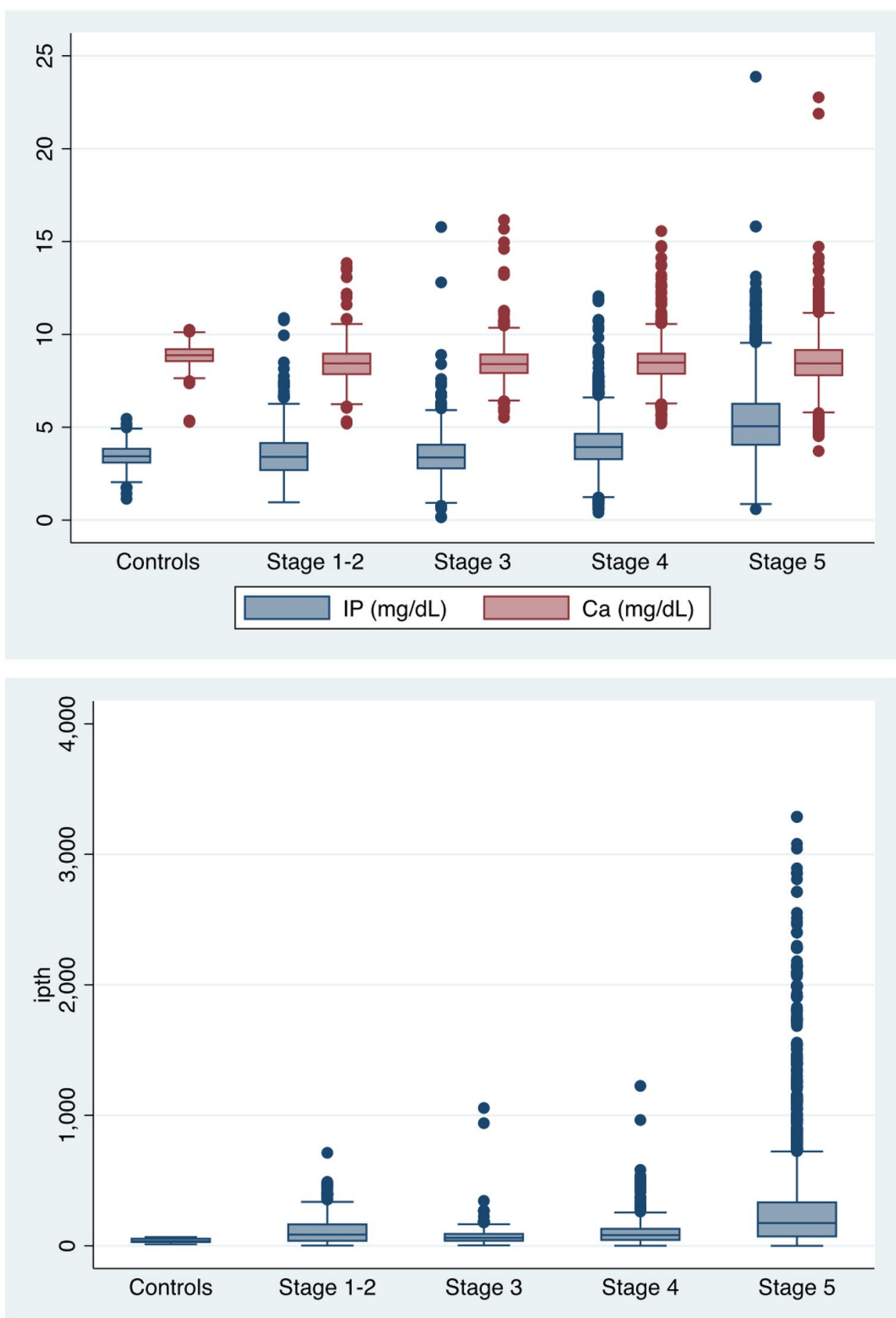

and intact parathyroid hormone increased the risk of only advanced stages. Moreover, the risk prediction of these markers was more evident in males and hypertensive subjects. Our findings suggest that mineral metabolism markers may help identify subgroups at high risk of having CKD or advancing to advanced stages.

Our findings are biologically plausible. Growing evidence indicates that calcium and phosphorus homeostasis plays an important role in the pathophysiology of CKD. Some researchers reported that increased parathyroid hormone occurred before abnormalities in serum calcium and phosphate concentrations [29], and it can maintain serum calcium within normal physiological ranges via increasing calcium efflux from bone, renal calcium reabsorption, and phosphate excretion. Moreover, increased secretion of parathyroid hormone can stimulate renal phosphate excretion in CKD [30], 
Fig. 2 Correlation between serum inorganic phosphorus (IP), serum calcium (Ca), and intact parathyroid hormone (i-PTH) among all study subjects

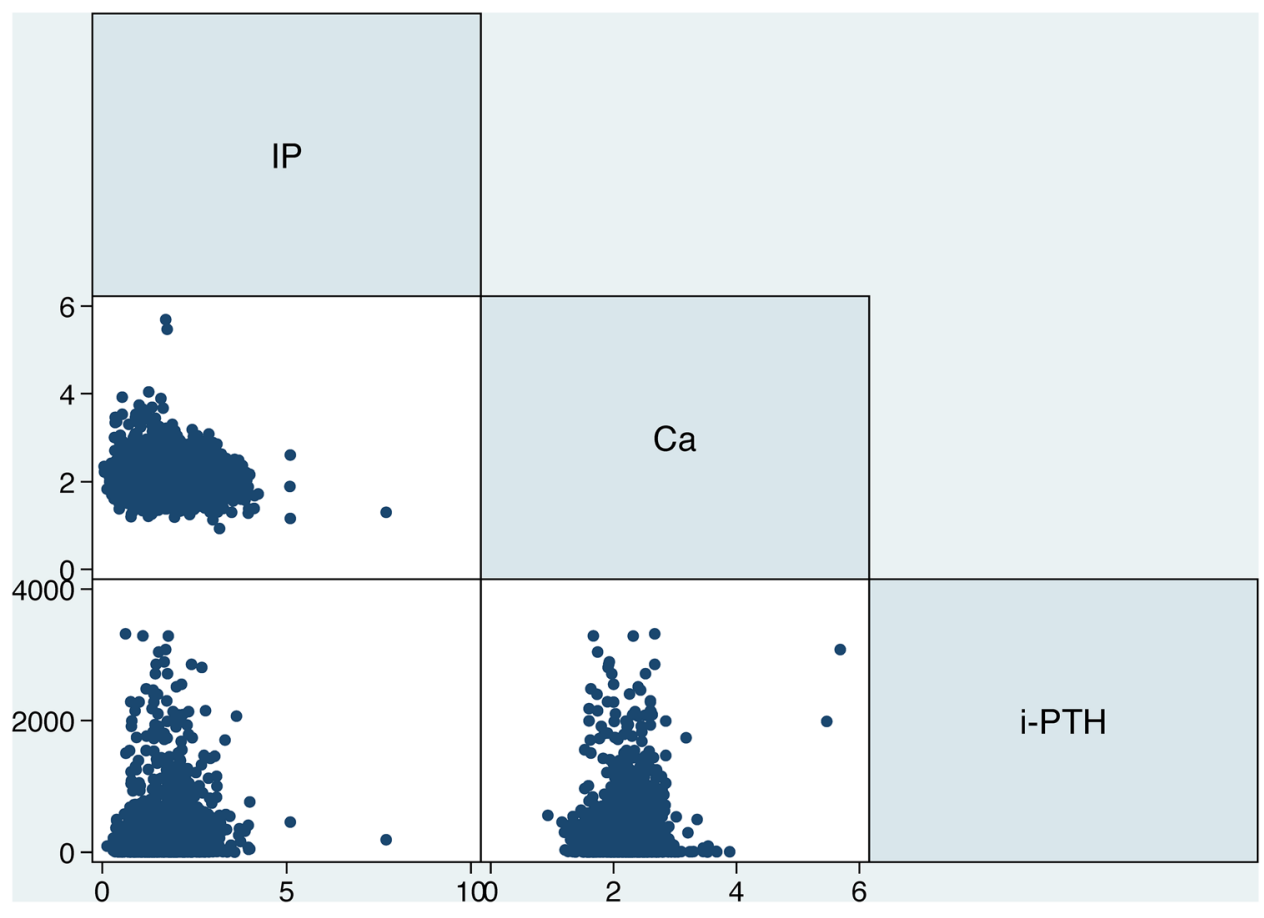

Table 2 Risk prediction of mineral metabolism markers for chronic kidney disease (CKD) at different stages in propensity score matching analysis

\begin{tabular}{lllll}
\hline Significant risk factors & CKD stage $1-2$ & CKD stage 3 & CKD stage 4 & CKD stage 5 \\
\hline Ca $(0.5 \mathrm{mg} / \mathrm{dL}$ increment) & $0.66,0.54$ to $0.81,<0.001$ & $0.61,0.49$ to $0.77,<0.001$ & $0.55,0.44$ to $0.69,<0.001$ & $0.72,0.61$ to $0.86,<0.001$ \\
IP $(0.5 \mathrm{mg} / \mathrm{dL}$ increment $)$ & $1.33,1.14$ to $1.55,<0.001$ & $0.97,0.81$ to $1.16,0.748$ & $1.61,1.35$ to $1.91,<0.001$ & $2.85,2.21$ to 3.68, $<0.001$ \\
Ca $\times$ IP $\left(5 \mathrm{mg}^{2} / \mathrm{dL}^{2}\right.$ increment $)$ & $1.07,0.96$ to $1.21,0.227$ & $0.97,0.83$ to $1.12,0.660$ & $1.28,1.09$ to $1.38,0.001$ & $2.19,1.82$ to $2.62,<0.001$ \\
i-PTH $\left(8 \mathrm{pg} / \mathrm{mL}_{\text {increment }}\right)$ & $1.06,1.00$ to $1.13,0.040$ & $1.01,0.97$ to $1.05,0.548$ & $1.10,1.03$ to $1.17,0.004$ & $1.09,1.04$ to $1.14,<0.001$ \\
\hline
\end{tabular}

$C a$ serum calcium, IP inorganic phosphorus, $i$-PTH intact parathyroid hormone, $C a \times I P$ calcium-phosphorus product

Data are expressed as odds ratio, $95 \%$ confidence interval, $P$ value

and parathyroid hormone secretion increased in response to changes in calcium and phosphate [29]. Based on above evidence, it is reasonable to speculate that abnormalities in mineral homeostasis are implicated in the development and progression of CKD.

Our findings reinforced this speculation by demonstrating that serum calcium was a predictive factor for all-stage CKD, yet inorganic phosphorus, calcium-phosphorus product, and intact parathyroid hormone were risk factors for its advanced stages. The study by Rouached and colleagues showed that high intact parathyroid hormone may less likely happen with estimated glomerular filtration rate greater than $80 \mathrm{ml} / \mathrm{min}$, and serum calcium and inorganic phosphorus can be maintained in normal ranges until estimated glomerular filtration rate is less than $40 \mathrm{ml} / \mathrm{min}$ [29]. Extending the results of this study [29], our analysis revealed that serum calcium concentrations were significantly lower in patients at all stages, indicating that serum calcium is a robust indicator of CKD.
It is widely recognized early monitoring of serum mineral metabolism markers is important for public health planning. Currently, most studies examining mineral metabolism markers and CKD are restricted to advanced stages [31, 32]. Although the 2017 KDIGO guidelines of CKD-MBD have recommended monitoring serum concentrations of calcium, phosphorus, and intact parathyroid hormone beginning in stage $3 \mathrm{CKD}$, our subsidiary analyses indicated that the risk prediction of these markers hinged upon sex and hypertension status. For instance, intact parathyroid hormone was associated with the significantly increased risk of stages 1-2 and 4-5 CKD in men or hypertensive subjects, whereas this association remained nonsignificant in women or normotensive subjects. Additionally, Bellasi and colleagues in a prospective study reported that the magnitude of risk associated with hyperphosphatemia varied depending on age, sex, diabetes, and different stages of CKD [33], which can 
Table 3 Risk prediction of mineral metabolism markers for chronic kidney disease (CKD) at different stages in subsidiary analyses

\begin{tabular}{|c|c|c|c|c|}
\hline Significant risk factors & CKD stage $1-2$ & CKD stage 3 & CKD stage 4 & CKD stage 5 \\
\hline \multicolumn{5}{|l|}{ Age $<60$ years } \\
\hline $\mathrm{Ca}(0.5 \mathrm{mg} / \mathrm{dL}$ increment $)$ & 0.670 .55 to $0.83,<0.001$ & $0.74,0.61$ to $0.91,0.004$ & $0.77,0.68$ to $0.87,<0.001$ & $0.89,0.84$ to $0.95,0.001$ \\
\hline IP $(0.5$ mg/dL increment $)$ & $1.18,1.04$ to $1.34,0.011$ & $0.98,0.84$ to $1.15,0.846$ & $1.24,1.12$ to $1.37,<0.001$ & $1.58,1.44$ to $1.73,<0.001$ \\
\hline $\mathrm{Ca} \times \operatorname{IP}\left(5 \mathrm{mg}^{2} / \mathrm{dL}^{2}\right.$ increment $)$ & $1.09,0.95$ to $1.25,0.202$ & $0.88,0.73$ to $1.05,0.145$ & $1.14,1.02$ to $1.28,0.016$ & $1.47,1.34$ to $1.62,<0.001$ \\
\hline i-PTH (8 pg/mL increment) & $1.24,1.06$ to $1.45,0.006$ & $1.75,1.10$ to $2.77,0.017$ & $1.25,1.09$ to $1.44,0.001$ & $1.13,1.05$ to $1.21,0.001$ \\
\hline \multicolumn{5}{|l|}{ Age $>60$ years } \\
\hline $\mathrm{Ca}(0.5 \mathrm{mg} / \mathrm{dL}$ increment $)$ & $0.76,0.67$ to $0.85,<0.001$ & $0.83,0.75$ to $0.91,<0.001$ & $0.85,0.79$ to $0.92,<0.001$ & $0.87,0.81$ to $0.94,<0.001$ \\
\hline IP $(0.5 \mathrm{mg} / \mathrm{dL}$ increment $)$ & $1.00,0.92$ to $1.09,0.938$ & $1.03,0.95$ to $1.11,0.439$ & $1.31,1.20$ to $1.43,<0.001$ & $1.61,1.49$ to $1.75,<0.001$ \\
\hline $\mathrm{Ca} \times \operatorname{IP}\left(5 \mathrm{mg}^{2} / \mathrm{dL}^{2}\right.$ increment $)$ & $0.93,0.84$ to $1.02,0.120$ & $0.99,0.89$ to $1.05,0.458$ & $1.23,1.13$ to $1.35,<0.001$ & $1.58,1.45$ to $1.71,<0.001$ \\
\hline i-PTH (8 pg/mL increment) & $1.20,1.04$ to $1.39,0.011$ & $1.25,1.05$ to $1.49,0.013$ & $1.24,1.10$ to $1.41,<0.001$ & $1.18,1.09$ to $1.29,<0.001$ \\
\hline \multicolumn{5}{|l|}{ Men } \\
\hline $\mathrm{Ca}(0.5 \mathrm{mg} / \mathrm{dL}$ increment $)$ & $0.68,0.58$ to $0.81,<0.001$ & $0.70,0.58$ to $0.85,<0.001$ & $0.56,0.46$ to $0.67,<0.001$ & $0.76,0.66$ to $0.88,<0.001$ \\
\hline IP $(0.5 \mathrm{mg} / \mathrm{dL}$ increment $)$ & $1.14,1.01$ to $1.27,0.027$ & $1.16,1.00$ to $1.35,0.043$ & $1.42,1.24$ to $1.63,<0.001$ & $2.65,2.15$ to $3.27,<0.001$ \\
\hline $\mathrm{Ca} \times \operatorname{IP}\left(5 \mathrm{mg}^{2} / \mathrm{dL}^{2}\right.$ increment $)$ & $1.05,0.93$ to $1.19,0.434$ & $1.04,0.89$ to $1.22,0.620$ & $1.28,1.12$ to $1.46,<0.001$ & $2.34,1.93$ to $2.83,<0.001$ \\
\hline i-PTH (8 pg/mL increment) & $1.56,1.22$ to $1.99,<0.001$ & $1.42,1.05$ to $1.90,0.021$ & $1.72,1.33$ to $2.22,<0.001$ & $1.29,1.13$ to $1.46,<0.001$ \\
\hline \multicolumn{5}{|l|}{ Women } \\
\hline $\mathrm{Ca}(0.5 \mathrm{mg} / \mathrm{dL}$ increment $)$ & $0.42,0.26$ to $0.67,<0.001$ & $0.61,0.44$ to $0.84,0.002$ & $0.53,0.37$ to $0.77,0.001$ & $0.83,0.63$ to $1.08,0.169$ \\
\hline $\mathrm{IP}(0.5 \mathrm{mg} / \mathrm{dL}$ increment $)$ & $1.15,0.92$ to $1.44,0.210$ & $1.05,0.91$ to $1.23,0.460$ & $1.11,0.95$ to $1.29,0.178$ & $1.60,1.22$ to $2.08,0.001$ \\
\hline $\mathrm{Ca} \times \operatorname{IP}\left(5 \mathrm{mg}^{2} / \mathrm{dL}^{2}\right.$ increment $)$ & $1.00,0.78$ to $1.27,0.990$ & $1.00,0.86$ to $1.18,0.966$ & $1.04,0.90$ to $1.22,0.565$ & $1.51,1.15$ to $1.96,0.002$ \\
\hline i-PTH (8 pg/mL increment) & $1.68,0.67$ to $4.25,0.269$ & $1.42,0.67$ to $3.04,0.357$ & $1.34,0.87$ to $2.07,0.188$ & $1.17,0.85$ to $1.61,0.330$ \\
\hline \multicolumn{5}{|l|}{ Hypertension } \\
\hline $\mathrm{Ca}(0.5 \mathrm{mg} / \mathrm{dL}$ increment $)$ & $0.61,0.48$ to $0.78,<0.001$ & $0.59,0.46$ to $0.75,<0.001$ & $0.58,0.46$ to $0.73,<0.001$ & $0.73,0.61$ to $0.88,0.001$ \\
\hline IP $(0.5 \mathrm{mg} / \mathrm{dL}$ increment $)$ & $1.49,1.26$ to $1.77,<0.001$ & $1.08,0.95$ to $1.23,0.222$ & $1.29,1.11$ to $1.50,0.001$ & $3.13,2.35$ to $4.19,<0.001$ \\
\hline $\mathrm{Ca} \times \operatorname{IP}\left(5 \mathrm{mg}^{2} / \mathrm{dL}^{2}\right.$ increment $)$ & $1.37,1.15$ to $1.61,<0.001$ & $1.00,0.86$ to $1.17,0.951$ & $1.19,1.03$ to $1.39,0.022$ & $2.56,2.00$ to $3.27,<0.001$ \\
\hline i-PTH (8 pg/mL increment) & $1.45,1.13$ to $1.85,0.003$ & $1.69,1.08$ to $2.65,0.022$ & $1.32,1.10$ to $1.59,0.003$ & $1.29,1.12$ to $1.50,0.001$ \\
\hline \multicolumn{5}{|l|}{ Without hypertension } \\
\hline $\mathrm{Ca}(0.5 \mathrm{mg} / \mathrm{dL}$ increment $)$ & $0.54,0.39$ to $0.75,<0.001$ & $0.92,0.73$ t0 $1.16,0.484$ & $0.63,0.48$ to $0.83,0.001$ & $0.66,0.48$ to $0.90,0.008$ \\
\hline IP $(0.5 \mathrm{mg} / \mathrm{dL}$ increment $)$ & $0.62,0.46$ to $0.85,0.002$ & $1.03,0.84$ to $1.26,0.789$ & $1.41,1.11$ to $1.79,0.005$ & $1.69,1.28$ to $2.25,<0.001$ \\
\hline $\mathrm{Ca} \times \mathrm{IP}\left(5 \mathrm{mg}^{2} / \mathrm{dL}^{2}\right.$ increment $)$ & $0.54,0.40$ to $0.75,<0.001$ & $0.99,0.79$ to $1.23,0.934$ & $1.21,0.94$ to $1.55,0.133$ & $1.44,1.11$ to $1.86,0.005$ \\
\hline i-PTH (8 pg/mL increment) & $1.31,0.93$ to $1.85,0.129$ & $1.21,0.93$ to $1.56,0.153$ & $1.19,0.99$ to $1.48,0.109$ & $1.58,0.96$ to $2.59,0.070$ \\
\hline \multicolumn{5}{|l|}{ Diabetes mellitus } \\
\hline $\mathrm{Ca}(0.5 \mathrm{mg} / \mathrm{dL}$ increment $)$ & $0.72,0.54$ to $0.96,0.025$ & $0.96,0.74$ to $1.24,0.751$ & $0.68,0.53$ to $0.86,0.002$ & $0.64,0.44$ to $0.91,0.014$ \\
\hline IP $(0.5 \mathrm{mg} / \mathrm{dL}$ increment $)$ & $1.23,1.01$ to $1.49,0.036$ & $0.95,0.73$ to $1.23,0.696$ & $1.35,1.12$ to $1.63,0.002$ & $2.08,1.46$ to $2.97,<0.001$ \\
\hline $\mathrm{Ca} \times \mathrm{IP}\left(5 \mathrm{mg}^{2} / \mathrm{dL}^{2}\right.$ increment $)$ & $1.16,0.96$ to $1.41,0.127$ & $0.94,0.73$ to $1.22,0.651$ & $1.27,1.06$ to $1.51,0.009$ & $1.89,1.35$ to $2.62,<0.001$ \\
\hline i-PTH (8 pg/mL increment) & $1.31,1.06$ to $1.64,0.014$ & $1.72,1.12$ to $2.65,0.013$ & $1.42,1.14$ to $1.77,0.002$ & $1.27,1.03$ to $1.57,0.023$ \\
\hline \multicolumn{5}{|l|}{ Without diabetes mellitus } \\
\hline $\mathrm{Ca}(0.5 \mathrm{mg} / \mathrm{dL}$ increment $)$ & $0.57,0.45$ to $0.72,<0.001$ & $0.80,0.65$ to $0.99,0.037$ & $0.57,0.44$ to $0.73,<0.001$ & $0.78,0.67$ to $0.91,0.002$ \\
\hline IP $(0.5 \mathrm{mg} / \mathrm{dL}$ increment $)$ & $1.13,0.99$ to $1.30,0.069$ & $1.07,0.92$ to $1.21,0.380$ & $1.31,1.12$ to $1.54,0.001$ & $2.57,2.02$ to $3.26,<0.001$ \\
\hline $\mathrm{Ca} \times \mathrm{IP}\left(5 \mathrm{mg}^{2} / \mathrm{dL}^{2}\right.$ increment $)$ & $1.03,0.89$ to $1.19,0.706$ & $0.98,0.81$ to $1.17,0.814$ & $1.19,1.01$ to $1.40,0.032$ & $2.33,1.86$ to $2.94,<0.001$ \\
\hline i-PTH (8 pg/mL increment) & $1.23,0.98$ to $1.53,0.069$ & $1.23,0.86$ to $1.74,0.245$ & $1.21,0.99$ to $1.48,0.061$ & $1.17,1.01$ to $1.35,0.039$ \\
\hline
\end{tabular}

$I P$ inorganic phosphorus, $\mathrm{Ca}$ serum calcium, $i$-PTH intact parathyroid hormone, $\mathrm{Ca} \times I P$ calcium-phosphorus product

Data are expressed as odds ratio, $95 \%$ confidence interval, $P$ value

consolidate the subsidiary results of the present study. Further, another cohort study by De Boer and colleagues demonstrated that the association between parathyroid hormone and chronic renal insufficiency differed across races. In view of this racial-dependent assocaition, we agree that it is of importance to establish data on the risk prediction of mineral metabolism markers for the risk and severity of CKD in each racial or ethnical group.

What's more, we constructed nomogram models for different stages of CKD after propensity score matching analysis, with decent prediction accuracy. For practical reasons, these nomogram models can be used in routine clinical 
Table 4 Prediction accuracy gained by adding mineral metabolism markers to the basic model for chronic kidney disease (CKD) at different stages

\begin{tabular}{|c|c|c|c|c|c|c|c|c|}
\hline \multirow[t]{2}{*}{ Statistics } & \multicolumn{4}{|c|}{ CKD stage $1-2$} & \multicolumn{4}{|l|}{ CKD stage 3} \\
\hline & Basic model & $\begin{array}{l}\text { Basic } \\
\text { model plus } \\
\mathrm{Ca}\end{array}$ & $\begin{array}{l}\text { Basic } \\
\text { model plus } \\
\text { IP }\end{array}$ & $\begin{array}{l}\text { Basic model } \\
\text { plus i-PTH }\end{array}$ & Basic model & $\begin{array}{l}\text { Basic } \\
\text { model plus } \\
\mathrm{Ca}\end{array}$ & Basic model plus IP & $\begin{array}{l}\text { Basic } \\
\text { model plus } \\
\text { i-PTH }\end{array}$ \\
\hline \multicolumn{9}{|l|}{ Calibration } \\
\hline AIC & 926.7 & 864.5 & 924.6 & 122.9 & 903.2 & 854.5 & 904.4 & 78.8 \\
\hline BIC & 958.7 & 900.9 & 961.1 & 148.0 & 936.2 & 892.1 & 942.1 & 101.2 \\
\hline LR test $\left(\chi^{2}\right)$ & Ref & 61.02 & 0.35 & 17.1 & Ref & 48.7 & 0.8 & 27.5 \\
\hline LR test $\mathrm{P}$ & Ref & $<0.001$ & 0.555 & $<0.001$ & Ref & $<0.001$ & 0.3750 & $<0.001$ \\
\hline \multicolumn{9}{|l|}{ Discrimination } \\
\hline NRI (P) & Ref & $<0.001$ & 0.4038 & 0.0015 & Ref & 0.0002 & 0.5418 & 0.0012 \\
\hline IDI (P) & Ref & $<0.001$ & 0.7059 & $<0.001$ & Ref & $<0.001$ & 0.04376 & $<0.001$ \\
\hline \multirow[t]{2}{*}{ Statistics } & \multicolumn{4}{|l|}{ CKD stage 4} & \multicolumn{4}{|l|}{ CKD stage 5} \\
\hline & Basic model & $\begin{array}{l}\text { Basic } \\
\text { model plus } \\
\mathrm{Ca}\end{array}$ & $\begin{array}{l}\text { Basic } \\
\text { model plus } \\
\text { IP }\end{array}$ & $\begin{array}{l}\text { Basic model } \\
\text { plus i-PTH }\end{array}$ & Basic model & $\begin{array}{l}\text { Basic } \\
\text { model plus } \\
\mathrm{Ca}\end{array}$ & Basic model plus IP & $\begin{array}{l}\text { Basic } \\
\text { model plus } \\
\text { i-PTH }\end{array}$ \\
\hline \multicolumn{9}{|l|}{ Calibration } \\
\hline AIC & 1160.3 & 1108.3 & 1151.7 & 169.15 & 1525.2 & 1491.5 & 1310.2 & 204.4 \\
\hline $\mathrm{BIC}$ & 1197.4 & 1150.7 & 1194.1 & 202.74 & 1567.9 & 1540.3 & 1359.1 & 249.1 \\
\hline LR test $\left(\chi^{2}\right)$ & Ref & 52.9 & 10.5 & 33.1 & Ref & 35.2 & 216.7 & 63.9 \\
\hline LR test $\mathrm{P}$ & Ref & $<0.001$ & 0.001 & $<0.001$ & Ref & $<0.001$ & $<0.001$ & $<0.001$ \\
\hline \multicolumn{9}{|l|}{ Discrimination } \\
\hline NRI (P) & Ref & $<0.001$ & 0.0441 & 0.0030 & Ref & 0.7340 & $<0.001$ & 0.0156 \\
\hline IDI (P) & Ref & $<0.001$ & 0.0154 & $<0.001$ & Ref & $<0.001$ & $<0.001$ & $<0.001$ \\
\hline
\end{tabular}

AIC Akaike information criterion, BIC Bayesian information criterion, $L R$ likelihood ratio, NRI net reclassification improvement, IDI integrated discrimination improvement, $I P$ inorganic phosphorus, $C a$ serum calcium, $i-P T H$ intact parathyroid hormone, Ref. reference group

Basic model included age, sex, hypertension, diabetes mellitus, triglycerides, total cholesterol, high-density lipoprotein cholesterol, and uric acid

practice to facilitate clinical decision-making and the personalized management of CKD.

Several possible limitations should be acknowledged for this study. First, the present analysis was based on cross-sectional data, which will preclude further comments on causality inference, especially the trajectory of CKD progression. Second, some unmeasured characteristics of study subjects such as smoking, drinking, dietary habits, as well as drug regimens such as RAS inhibitors and/or statins might confound the association of mineral metabolism markers with CKD [34]. Third, all study subjects were recruited from a mono center, which might raise a possibility of population stratification.
Despite these limitations, our findings indicate that serum calcium was associated with the risk of all-stage CKD, whereas the association for inorganic phosphorus, calcium-phosphorus product, and intact parathyroid hormone was significant at advanced stages. Importantly, the prediction capability of these markers was more evident in men and hypertensive subjects. Hence, more attention should be given to the balance of mineral metabolism markers even in patients with early stages of CKD to control and prevent the development and progression. We also agree that further investigations on the molecular mechanisms linking mineral metabolism markers and CKD are warranted. 
Fig. 3 Nomogram prediction models on the basis of age, sex, and three mineral metabolism markers (serum inorganic (Ca), and intact parathyroid hormone (i-PTH)) for stage 1-2 C), and 5 (panel D) chronic kidney disease, respectively. Sex was not incorporated in the nomogram for stage 3 due to nonsignificant effect phosphorus (IP), serum calcium (panel A), 3 (panel B), 4 (panel

A

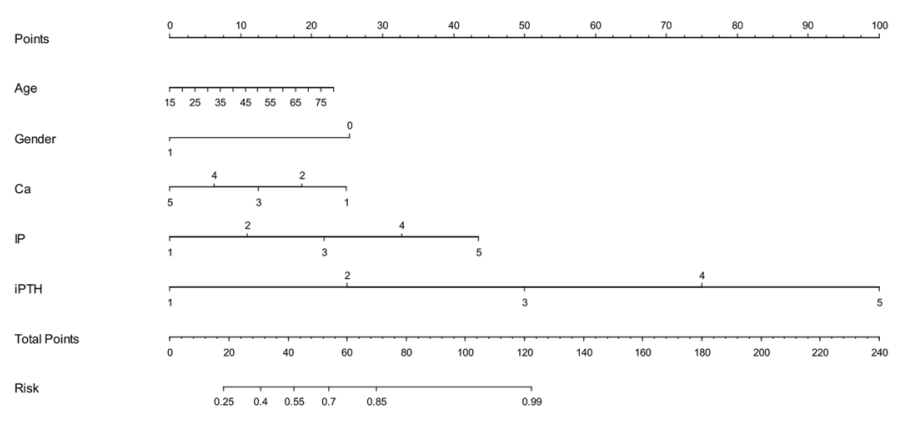

B

C

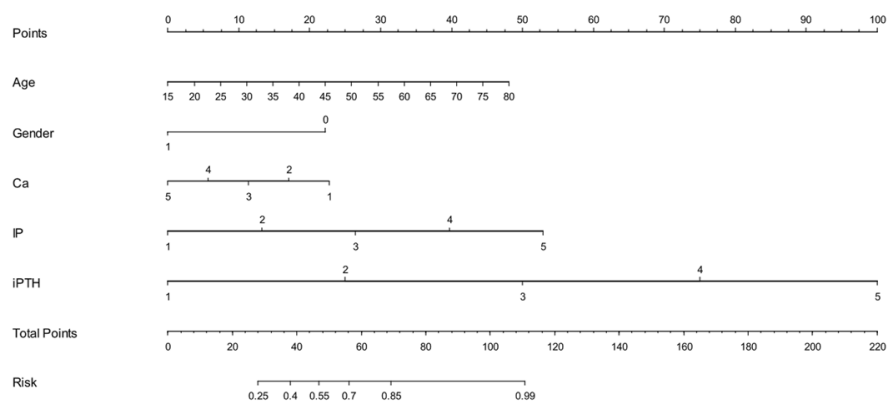

$\mathrm{D}$

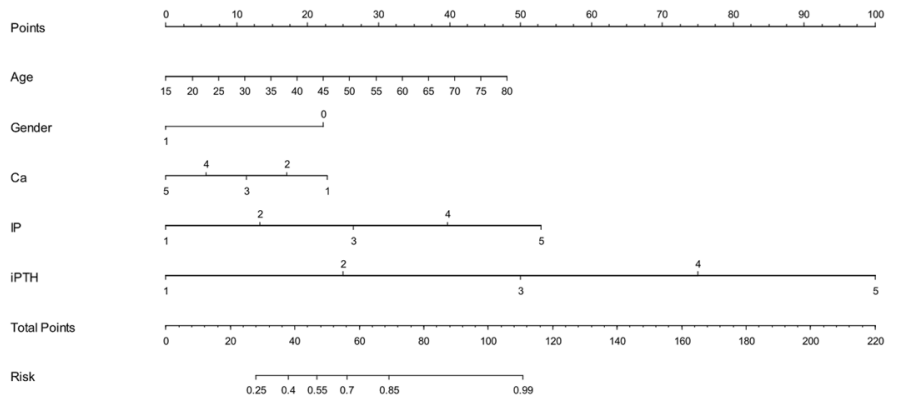

Acknowledgment We are grateful to all participating patients for their cooperation and willingness.

Author contribution PL planned and designed the study, and directed its implementation. PL drafted the protocol. XW and ML obtained statutory and ethics approvals. JL, ML and YW contributed to data acquisition. JL and DH conducted statistical analyses. WZ and MY did the data preparation and quality control. JL, WN and PL wrote the manuscript. All authors read and approved the final manuscript prior to submission.

Funding This work was supported by the Key Projects in the National Science \& Technology Pillar Program during Twelfth Five-Year Plan 
Period of China (Grant No. 2013BAI02B04), and the National Natural Science Foundation of China (Grant No.81620108031).

\section{Compliance with ethical standards}

Conflict of interest The authors have declared that no conflicts of interest exists.

Informed consent Informed consent was obtained from all individual participants included in the study.

Open Access This article is licensed under a Creative Commons Attribution 4.0 International License, which permits use, sharing, adaptation, distribution and reproduction in any medium or format, as long as you give appropriate credit to the original author(s) and the source, provide a link to the Creative Commons licence, and indicate if changes were made. The images or other third party material in this article are included in the article's Creative Commons licence, unless indicated otherwise in a credit line to the material. If material is not included in the article's Creative Commons licence and your intended use is not permitted by statutory regulation or exceeds the permitted use, you will need to obtain permission directly from the copyright holder. To view a copy of this licence, visit http://creativecommons.org/licenses/by/4.0/.

\section{References}

1. Jha V, Garcia-Garcia G, Iseki K, Li Z, Naicker S, Plattner B, et al. Chronic kidney disease: global dimension and perspectives. Lancet. 2013;382(9888):260-72. https://doi.org/10.1016/S0140 $-6736(13) 60687-X$

2. Saran R, Robinson B, Abbott KC, Agodoa LYC, Bragg-Gresham J, Balkrishnan R, et al. US renal data system 2018 annual data report: epidemiology of kidney disease in the United States. Am J Kidney Dis. 2019;73(3S1):A7-8.

3. Zhang L, Wang F, Wang L, Wang W, Liu B, Liu J, et al. Prevalence of chronic kidney disease in China: a cross-sectional survey. Lancet. 2012;379(9818):815-22. https://doi.org/10.1016/ S0140-6736(12)60033-6.

4. Robinson BM, Zhang J, Morgenstern H, Bradbury BD, Ng LJ, McCullough KP, et al. Worldwide, mortality risk is high soon after initiation of hemodialysis. Kidney Int. 2014;85(1):158-65. https://doi.org/10.1038/ki.2013.252.

5. Wong KK, Velasquez A, Powe NR, Tuot DS. Association between health literacy and self-care behaviors among patients with chronic kidney disease. BMC Nephrol. 2018;19(1):196. https://doi.org/10.1186/s12882-018-0988-0.

6. Inker LA, Grams ME, Levey AS, Coresh J, Cirillo M, Collins $\mathrm{JF}$, et al. Relationship of estimated GFR and albuminuria to concurrent laboratory abnormalities: an individual participant data meta-analysis in a global consortium. Am J Kidney Dis. 2019;73(2):206-17. https://doi.org/10.1053/j.ajkd.2018.08.013.

7. Cai G, Chen X. Hypertension in patients with CKD in China: clinical characteristics and management. Front Med. 2017;11(3):307-9. https://doi.org/10.1007/s11684-017-0578-8.

8. Fukui A, Yokoo T, Nangaku M, Kashihara N. New measures against chronic kidney diseases in Japan since 2018. Clin Exp Nephrol. 2019;23(11):1263-71. https://doi.org/10.1007/s1015 7-019-01786-7.

9. Block GA, Klassen PS, Lazarus JM, Ofsthun N, Lowrie EG, Chertow GM. Mineral metabolism, mortality, and morbidity in maintenance hemodialysis. J Am Soc Nephrol.
2004;15(8):2208-18. https://doi.org/10.1097/01.ASN.00001 33041.27682.A2.

10. Ganesh SK, Stack AG, Levin NW, Hulbert-Shearon T, Port FK. Association of elevated serum $\mathrm{PO}(4), \mathrm{Ca} \times \mathrm{PO}(4)$ product, and parathyroid hormone with cardiac mortality risk in chronic hemodialysis patients. J Am Soc Nephrol. 2001;12(10):2131-8.

11. Stevens LA, Djurdjev O, Cardew S, Cameron EC, Levin A. Calcium, phosphate, and parathyroid hormone levels in combination and as a function of dialysis duration predict mortality: evidence for the complexity of the association between mineral metabolism and outcomes. J Am Soc Nephrol. 2004;15(3):770-9. https://doi. org/10.1097/01.asn.0000113243.24155.2f.

12. Reichel H, Deibert B, Schmidt-Gayk H, Ritz E. Calcium metabolism in early chronic renal failure: implications for the pathogenesis of hyperparathyroidism. Nephrol Dial Transplant. 1991;6(3):162-9. https://doi.org/10.1093/ndt/6.3.162.

13. Kestenbaum B, Sampson JN, Rudser KD, Patterson DJ, Seliger SL, Young B, et al. Serum phosphate levels and mortality risk among people with chronic kidney disease. J Am Soc Nephrol. 2005;16(2):520-8. https://doi.org/10.1681/ASN.2004070602.

14. Hirano D, Inoue E, Sako M, Ashida A, Honda M, Takahashi S, et al. Clinical characteristics at the renal replacement therapy initiation of Japanese pediatric patients: a nationwide crosssectional study. Clin Exp Nephrol. 2020;24(1):82-7. https://doi. org/10.1007/s10157-019-01788-5.

15. Isakova T, Nickolas TL, Denburg M, Yarlagadda S, Weiner DE, Gutierrez OM, et al. KDOQI US commentary on the 2017 KDIGO clinical practice guideline update for the diagnosis, evaluation, prevention, and treatment of chronic kidney diseasemineral and bone disorder (CKD-MBD). Am J Kidney Dis. 2017;70(6):737-51. https://doi.org/10.1053/j.ajkd.2017.07.019.

16. Ketteler M, Block GA, Evenepoel P, Fukagawa M, Herzog CA, McCann L, et al. Diagnosis, evaluation, prevention, and treatment of chronic kidney disease-mineral and bone disorder: synopsis of the kidney disease: improving global outcomes 2017 clinical practice guideline update. Ann Intern Med. 2018;168(6):422-30. https://doi.org/10.7326/M17-2640.

17. Hara A, Koshino Y, Kurokawa Y, Shinozaki Y, Miyake T, Kitajima S, et al. Relationship between anti-erythropoietin receptor autoantibodies and responsiveness to erythropoiesis-stimulating agents in patients on hemodialysis: a multi-center cross-sectional study. Clin Exp Nephrol. 2020;24(1):88-95. https://doi. org/10.1007/s10157-019-01787-6.

18. Kidney Disease: Improving Global Outcomes (KDIGO) CKD Work Group. KDIGO. clinical practice guideline for the evaluation and management of chronic kidney disease. Kidney Int Suppl. 2012;2013(3):1-150.

19. Hsu CY. CKD-EPI eGFR categories were better than MDRD categories for predicting mortality in a range of populations. Annals of internal medicine. 2012;157(10):JC5-12. doi:https:// doi.org/10.7326/0003-4819-157-10-201211200-02012.

20. Matsushita K, Mahmoodi BK, Woodward M, Emberson JR, Jafar $\mathrm{TH}$, Jee $\mathrm{SH}$, et al. Comparison of risk prediction using the CKDEPI equation and the MDRD study equation for estimated glomerular filtration rate. JAMA. 2012;307(18):1941-51. https://doi. org/10.1001/jama.2012.3954.

21. Matsushita K, Tonelli M, Lloyd A, Levey AS, Coresh J, Hemmelgarn BR, et al. Clinical risk implications of the CKD Epidemiology Collaboration (CKD-EPI) equation compared with the Modification of Diet in Renal Disease (MDRD) Study equation for estimated GFR. Am J Kidney Dis. 2012;60(2):241-9. https:// doi.org/10.1053/j.ajkd.2012.03.016.

22. Stevens LA, Schmid CH, Greene T, Zhang YL, Beck GJ, Froissart $\mathrm{M}$, et al. Comparative performance of the CKD Epidemiology Collaboration (CKD-EPI) and the Modification of Diet in Renal 
Disease (MDRD) Study equations for estimating GFR levels above $60 \mathrm{~mL} / \mathrm{min} / 1.73 \mathrm{~m} 2$. Am J kidney Dis. 2010;56(3):486-95.

23. Levey AS, Stevens LA, Schmid CH, Zhang YL, Castro AF 3rd, Feldman HI, et al. A new equation to estimate glomerular filtration rate. Ann Intern Med. 2009;150(9):604-12. https://doi. org/10.7326/0003-4819-150-9-200905050-00006.

24. Chobanian AV, Bakris GL, Black HR, Cushman WC, Green LA, Izzo JL Jr, Jones DW, Materson BJ, Oparil S, Wright JT Jr, Roccella EJ, National Heart, Lung, and Blood Institute Joint National, Committee on Prevention D, Evaluation, and Treatment of High Blood Pressure; National high blood pressure education program coordinating committee. The seventh report of the joint national committee on prevention, detection, evaluation, and treatment of high blood pressure: the JNC 7 report. JAMA. 2003;289:2560-72.

25. American DA. Diagnosis and classification of diabetes mellitus. Diabetes Care. 2013;36(Suppl 1):S67-74. https://doi.org/10.2337/ dc13-S067.

26. Pencina MJ, D’Agostino RB Sr, D’Agostino RB Jr, Vasan RS. Evaluating the added predictive ability of a new marker: from area under the ROC curve to reclassification and beyond. Stat Med. 2008;27(2):157-72. https://doi.org/10.1002/sim.2929 (discussion 207-12).

27. Pencina MJ, D'Agostino RB, Vasan RS. Statistical methods for assessment of added usefulness of new biomarkers. Clin Chem Lab Med. 2010;48(12):1703-11. https://doi.org/10.1515/ CCLM.2010.340.

28. Dupont WD, Plummer WD Jr. Power and sample size calculations for studies involving linear regression. Control Clin Trials. 1998;19:589-601.

29. Rouached M, El Kadiri BS, Al Rifai AM, Garabedian M, Fournier A. Prevalence of abnormal serum vitamin D, PTH, calcium, and phosphorus in patients with chronic kidney disease: results of the study to evaluate early kidney disease. Kidney Int. 2008;74(3):389-90. https://doi.org/10.1038/ki.2008.169.

30. Felsenfeld AJ, Levine BS, Rodriguez M. Pathophysiology of calcium, phosphorus, and magnesium dysregulation in chronic kidney disease. Semin Dial. 2015;28(6):564-77. https://doi. org/10.1111/sdi.12411.

31. De Boer IH, Gorodetskaya I, Young B, Hsu CY, Chertow GM. The severity of secondary hyperparathyroidism in chronic renal insufficiency is GFR-dependent, race-dependent, and associated with cardiovascular disease. J Am Soc Nephrol. 2002;13(11):2762-9. https://doi.org/10.1097/01.asn.0000034202.91413.eb.

32. Liabeuf S, McCullough K, Young EW, Pisoni R, Zee J, Reichel $\mathrm{H}$, et al. International variation in the management of mineral bone disorder in patients with chronic kidney disease: results from CKDopps. Bone. 2019;129:115058. https://doi.org/10.1016/j. bone.2019.115058.

33. Bellasi A, Mandreoli M, Baldrati L, Corradini M, Di Nicolo P, Malmusi G, et al. Chronic kidney disease progression and outcome according to serum phosphorus in mild-to-moderate kidney dysfunction. Clin J Am Soc Nephrol. 2011;6(4):883-91. https:// doi.org/10.2215/cjn.07810910.

34. Liu Z, Su G, Guo X, Wu Y, Liu X, Zou C, et al. Dietary interventions for mineral and bone disorder in people with chronic kidney disease. Cochrane Database Syst Rev. 2015;9:010350.

Publisher's Note Springer Nature remains neutral with regard to jurisdictional claims in published maps and institutional affiliations. 